\title{
A COMPARISON OF MOSQUITO CONSUMPTION AND PREY SELECTION BETWEEN LEAST CHUB (IOTICHTHYS PHLEGETHONTIS) AND WESTERN MOSQUITOFISH (GAMBUSIA AFFINIS)
}

\author{
Eric J. Billman ${ }^{1}$, Eric J. Wagner ${ }^{1,2}$, and Ronney E. Arndt ${ }^{1}$
}

\begin{abstract}
We compared mosquito consumption and prey selection between least chub (Iotichthys phlegethontis) and western mosquitofish (Gambusia affinis) to determine the potential of least chub as an indigenous replacement for mosquito control in Utah. Mosquito consumption was compared between the 2 species in 2 experiments. The first tested consumption at 3 ratios of pupae and larvae (Culex sp.; 1:3, 3:4, and 1:1), and the second tested consumption at varying densities of larvae (967 larvae $\cdot \mathrm{m}^{-3}, 1354$ larvae $\cdot \mathrm{m}^{-3}$, and 2258 larvae $\cdot \mathrm{m}^{-3}$ [30, 42, and 70 larvae per 31-L tank, respectively]). Western mosquitofish consumed more mosquitoes at lower pupae-to-larvae ratios than least chub, but least chub consumed more mosquitoes as the ratio of pupae to larvae increased. Western mosquitofish consumed significantly more larvae than least chub at all densities. Prey selection was compared between least chub and western mosquitofish, either individually or in intraspecific pairs, when the fish were fed equal abundances of 3 prey items: mosquito larvae, Daphnia magna, and midge larvae (Chironomid sp.). Least chub consumed significantly fewer total prey items for both the 1- and 2-fish trials; western mosquitofish consumed significantly more individuals of each prey type except for Daphnia magna in the 1-fish trials. Least chub and western mosquitofish demonstrated no selection for prey items, indicating that both fish would consume mosquito larvae at rates relative to abundance. Feeding habits demonstrated in this study indicated that least chub could be a potential replacement for western mosquitofish for mosquito control; however, field studies should be conducted to assess the ability of both species to control mosquitoes in a natural setting.
\end{abstract}

Key words: mosquito consumption, indigenous fish, least chub, Iotichthys phlegethontis, western mosquitofish, Gambusia affinis, prey selection.

The western mosquitofish (Gambusia affinis) has been introduced to various habitats throughout North America as a biological control for mosquitoes (Rupp 1996). When introduced into man-made systems, the western mosquitofish effectively reduces mosquito larvae and for that reason is utilized in mosquito abatement programs in many regions (Bay 1972). The western mosquitofish, however, has a broad diet, and is less effective at mosquito control when alternative food sources are present (Bence 1988, Linden and Cech 1990, Goodsell and Kats 1999). As a result, the western mosquitofish is less effective at mosquito control when introduced into natural systems outside its native range and often has adverse effects on native aquatic species (Schoenherr 1981, Kramer et al. 1987, Rupp 1996, Leyse et al. 2004).

The western mosquitofish was successfully introduced into Utah in 1932 to control mosquitos in Salt Lake City. Within 13 years it was found in other localities in the state (Rees 1934, Rees 1945a). Due to cold winter temperatures in Utah, the most favorable habitats for western mosquitofish are pools associated with springs where relatively constant water sources improve survival. Mosquito abatement programs continue to utilize western mosquitofish as a biological control, especially because of recent concerns about the spread of West Nile virus (CDC 2003).

The western mosquitofish has had negative impacts on Utah's native aquatic species (Lydeard and Belk 1993, Perkins et al. 1998, Mills et al. 2004). Least chub (Iotichthys phlegethontis) was once widely distributed in the Bonneville Basin in a variety of habitats scattered throughout Utah (Sigler and Sigler 1987). Anthropogenic disturbances have extirpated least chub from much of its historical range (Perkins et al. 1998), and the western mosquitofish is thought to be responsible for further declines of least chub through predation and

${ }^{1}$ Utah Division of Wildlife Resources, Fisheries Experiment Station, 1465 West 200 North, Logan, UT 84321.

2E-mail: ericwagner@utah.gov 
TABLe 1. Number of mosquitoes (Culex sp.), mosquito density, and pupae-to-larvae ratio fed to least chub (Iotichthys phlegethontis) and western mosquitofish (Gambusia affinis) in 2 consumption experiments. Volume of experimental tanks was $31 \mathrm{~L}$. Three replicates each of least chub, western mosquitofish, and no-fish controls were conducted for each trial.

\begin{tabular}{ccccc}
\hline Trial & Number of larvae & Number of pupae & $\begin{array}{c}\text { Density } \\
\left(\text { mosquitoes } \cdot \mathrm{m}^{-3} \text { ) }\right.\end{array}$ & Pupae: larvae \\
\hline $\begin{array}{c}\text { EXPERIMENT 1 } \\
1\end{array}$ & 8 & 6 & 451 & $3: 4$ \\
2 & 18 & 5 & 741 & $1: 3$ \\
3 & 11 & 11 & 709 & $1: 1$ \\
EXPERIMENT 2 & 30 & - & 967 & - \\
1 & 42 & - & 1354 & - \\
2 & 70 & - & 2258 & - \\
3 & & & & \\
\hline
\end{tabular}

competition (Perkins et al. 1998, Mills et al. 2004). Least chub is currently limited to a few isolated spring complexes, unfortunately the same habitats most conducive to overwinter survival of western mosquitofish.

Negative impacts of western mosquitofish necessitate studies comparing the efficacy of indigenous fish and western mosquitofish for mosquito control (Haas and Pal 1984). Fisheries managers in Utah have suggested using least chub in place of western mosquitofish. Least chub is an opportunistic feeder, commonly eating algae, copepods, ostracods, mosquito larvae, midge larvae and pupae, and other small invertebrates (Rees 1945a, Pendelton and Smart 1954, Sigler and Sigler 1996). Utilizing least chub for mosquito control could help restore populations of this species within its historical range. We compared mosquito consumption and prey selection between least chub and western mosquitofish. Mosquito larvae consumption was compared between least chub and western mosquitofish at varying ratios of pupae to larvae and at varying densities of larvae. Selectivity for mosquito larvae in the presence of other prey items was also compared between the 2 species.

\section{Methods}

Feeding studies were conducted at the Utah Division of Wildlife Resources' Fisheries Experiment Station (FES) in Logan. Least chub adults were obtained from a wild broodstock from Mona Springs, Utah, maintained at FES. Western mosquitofish were obtained from the Davis County Mosquito Abatement District in Kaysville, Utah. Prior to experiments, least chub and western mosquitofish were fed a commercial flake feed (Tetramin Pro $\left.{ }^{\circledR}\right)$ twice a day. We performed statistical analyses using SPSS version 7 (SPSS, Inc. 1996) and evaluated test statistics at a significance level of 0.05 .

\section{Consumption of \\ Mosquito Larvae}

We compared mosquito consumption between least chub and western mosquitofish in 2 experiments, 1 in August 2004 and the other in October 2004. Both experiments were conducted in outdoor circular tanks. Nine 31-L circular tanks, used as the experimental tanks, were filled with well water at $15.5^{\circ} \mathrm{C}$ and housed in a larger circular tank supplied with well water on a flow-through system that served as a water bath. Flow was not provided to the experimental tanks to avoid flushing out the mosquitoes. Airstones provided supplemental oxygen to each experimental tank. For the 1st experiment, we obtained mosquito larvae and pupae (Culex sp.) commercially from Aquatic Ecosystem, Inc. (Apopka, FL). For the 2nd experiment, mosquito eggs (Culex sp.) were obtained from Carolina Biological Supply (Burlington, NC) and hatched at the FES. Larvae were at least in the 3rd instar stage of development before use.

The 1st experiment compared mosquito consumption of least chub and western mosquitofish in 3 trials in which pupae and larvae were available at different ratios $(1: 3,3: 4$, and $1: 1$ [pupae:larvae]; Table 1). For each trial, consumption by three 5-fish groups of least chub was compared to consumption by three 5 -fish groups of western mosquitofish; 3 no-fish controls were used in each trial to evaluate counting and recapture accuracy for the mosquitoes. 
New fish were used for each trial. Mean lengths of the fish used for the 3 trials $(n=15$ for each species for each trial) ranged from $43.0 \mathrm{~mm}$ to $48.6 \mathrm{~mm}$ for least chub and from $34.4 \mathrm{~mm}$ to $43.4 \mathrm{~mm}$ for mosquitofish. Mean weights ranged from $0.9 \mathrm{~g}$ to $1.3 \mathrm{~g}$ for least chub and from $0.5 \mathrm{~g}$ to $1.3 \mathrm{~g}$ for mosquitofish. For each trial, temperatures fluctuated daily between $15.5^{\circ} \mathrm{C}$ and $18.9^{\circ} \mathrm{C}$. Prior to each trial, fish were introduced into randomly selected tanks and allowed to acclimate for 24 hours without food. After the acclimation period, mosquito larvae and pupae were introduced into each of the 9 tanks. After 24 hours, fish were removed, and the remaining mosquitoes were enumerated; percent consumption was determined for each tank.

The 2nd experiment compared mosquito consumption between the 2 species in 3 trials in which larvae were available at different densities (Table 1). For each trial, consumption by three 5-fish groups of least chub was compared to consumption by three 5-fish groups of western mosquitofish; 3 no-fish controls were used in each trial. New fish were used for each trial. Fish for each tank in the 2nd experiment were randomly selected from the fish used in the 1st experiment. For each trial, temperatures fluctuated daily between $14.2^{\circ} \mathrm{C}$ and $16.7^{\circ} \mathrm{C}$. After introduction into experimental tanks, the fish received 1 week of acclimation to minimize residual stress from handling. During the entire acclimation period, fish were fed $50 \mathrm{mg}$ of a tropical fish flake diet (Tetramin Pro ${ }^{\circledR}$ ) per tank twice per day. Every other day 10 mosquito larvae were added to each tank to familiarize the fish with the prey. Twenty-four hours prior to trial initiation, feed was withheld and the tanks were cleaned and scrutinized to ensure that no larvae remained from feeding during the acclimation phase. At the start of each trial, mosquito larvae were introduced into each of the 9 tanks. After 24 hours, fish were removed and the remaining mosquitoes were enumerated; percent consumption was determined for each tank.

Each experiment was analyzed individually. For the 1st experiment, the arcsin transform of the percent consumption data violated assumptions of normality and homogeneity of variances. Therefore, percent consumption data were rank-transformed prior to analysis. Differences in mosquito consumption between least chub, mosquito fish, and no-fish controls were compared using a 2-way analysis of vari- ance (ANOVA) with percent consumption as the response variable. Species and pupae-tolarvae ratio were the 2 fixed factors. For the 2nd experiment, percent consumption data were also rank-transformed prior to analysis because of assumption violations. Differences in mosquito consumption between species were compared using a 2-way ANOVA with percent consumption as the response variable and species and larvae densities as the 2 independent factors. Post hoc mean comparisons were made with a Tukey's test.

\section{Selectivity for \\ Mosquito Larvae}

Prey selectivity was tested in 1- and 2-fish groups in replicate trials between April 2005 and July 2005. Fish were presented 3 prey items: mosquito larvae, midge larvae (Chironomidae sp.), and Daphnia magna. Mosquito eggs were obtained from Carolina Biological Supply and hatched on station; mosquito larvae were 3rd and 4th instars before use in trials. Midge larvae were collected at FES in raceways that were not being used for culture purposes. Daphnia was obtained from Ward's Natural Science Establishment, Inc. (Rochester, NY) and maintained in culture at FES.

Least chub and western mosquitofish for the 1-fish trials were reused from the mosquito consumption test; new least chub and western mosquitofish were obtained for the 2fish trials. Least chub and mosquitofish were introduced into the test containers (19-L plastic containers) and fasted for 24 hours. Multiple containers (8-20) with equal replicates of each species and at least 2 no-fish controls were conducted simultaneously. New fish were used for each set of replicates. Aquaria were enclosed behind a curtain to minimize disturbance and illuminated by a full spectrum fluorescent light. After the acclimation period, equal numbers (20 each) of mosquito larvae, midge larvae, and Daphnia individuals were poured into the containers, and container contents were stirred immediately to thoroughly distribute the prey. Fish were allowed to feed for 2 hours in 1-fish trials. In 2 -fish trials, fish were only allowed 1 hour to feed because preliminary trials indicated that both species could consume all prey items within 2 hours, which would preclude the ability to determine prey selection. After the feeding period, fish were removed from the containers and uneaten prey items were enumerated. Temperatures ranged 
from $17.1^{\circ}-18.1^{\circ} \mathrm{C}$ for 1 -fish trials; water temperature for all 2-fish trials was $18.4^{\circ} \mathrm{C}$. We conducted 1-fish trials for 26 least chub and 18 western mosquitofish, and nine 2 -fish trials for each species. Trials during which fish did not consume any prey items were eliminated from analyses. No-fish controls were used in each group of trials ( 8 for 1 -fish trials and 2 for 2 -fish trials) to evaluate counting and recapturing accuracy for each prey type. The average number of mosquito larvae, midge larvae, and Daphnia transferred into the containers and subsequently recaptured for all 11 controls was 20, 19.8, and 19.8, with coefficients of variation $(\mathrm{CV}=100 \times s / \bar{x})$ of $0.0 \%, 2.0 \%$, and $2.0 \%$, respectively, indicating that these methods were performed with minimal error.

For both 1-fish and 2-fish trials, we used $t$ tests to detect differences between least chub and western mosquitofish in average percent consumption for total prey and then for each prey type individually. All tests had equal variances except for Daphnia in the 1-fish trials, for which a $t$ test with unequal variances was used. Percentages were arcsine-transformed prior to analysis. Prey selectivity was estimated by calculating Chesson's (1983) coefficient of selectivity,

$$
\alpha=\frac{r_{i} / p_{i}}{\sum_{i=1}^{m} r_{i} / p_{i}}
$$

where $r_{i}$ is the proportion of food type $i$ in the diet, $p_{i}$ is the proportion of food type $i$ in the environment, and $m$ is the number of prey types available. For each set of trials, mean selection coefficients and associated 95\% confidence intervals were compared with random feeding $(1 / m)$ to determine prey selectivity. We assumed positive selectivity if the $95 \%$ confidence intervals were above the random feeding line, neutral selectivity if the $95 \%$ confidence intervals overlapped the random feeding line, and negative selectivity if the 95\% confidence intervals were below the random feeding line.

\section{RESULTS}

\section{Consumption of \\ Mosquito Larvae}

In the 1st mosquito consumption experiment, we observed a significant interaction between species and pupae-to-larvae ratio $(F$ $=35.778, \mathrm{df}=4, P=0.016$; Fig. 1A). Western mosquitofish consumed nearly all mosquitoes regardless of pupae-to-larvae ratio. Conversely, the numbers of mosquitoes consumed by least chub increased as the pupae-to-larvae ratio increased, with percent consumption similar to western mosquitofish at the 1:1 pupae-tolarvae ratio. Both species consumed significantly more mosquitoes than the percentage lost in no-fish controls for each set of trials. In the 2nd mosquito consumption experiment, mosquito consumption was significantly different between the 2 species and the no-fish controls $(F=47.515$, df $=2, P<0.001$; Fig. 1B). Percent consumption was not significantly affected by mosquito larvae density $(F$ $=0.121, \mathrm{df}=2, P=0.887$ ).

\section{Selectivity for \\ Mosquito Larvae}

In 1-fish trials, 7 least chub and 1 western mosquitofish did not consume a prey item, and were not used in analyses; prey items were consumed in all 2-fish trials for both species. Least chub consumed significantly fewer prey items in the 1-fish trials than western mosquitofish $(11.1 \%$ and $23.9 \%$, respectively; $t=2.819$, df $=34, P=0.008)$. Both species consumed more prey in the 2 -fish trials; least chub again consumed significantly less prey than western mosquitofish $(53.7 \%$ and $89.6 \%$, respectively; $t=4.118, \mathrm{df}=16, P$ $=0.001)$. Western mosquitofish consumed significantly more individuals of each prey type than did least chub in both the 1-fish and 2 -fish trials (all $P$-values $<0.044$ ), with the exception of Daphnia in the 1-fish trials $(t=$ 0.67, $\mathrm{df}=42, P=0.254$ ).

Least chub and western mosquitofish demonstrated opportunistic feeding characteristics in selectivity trials. Both species neutrally selected all 3 prey types in the 1-fish and 2fish trials (Fig. 2). Western mosquitofish had higher selection coefficients for mosquito larvae, but because of high variation we could not conclude that western mosquitofish were more positively selective for mosquito larvae than were least chub.

\section{Discussion}

Least chub demonstrated that they would not only consume mosquitoes, but would consume mosquitoes in the presence of other prey. 


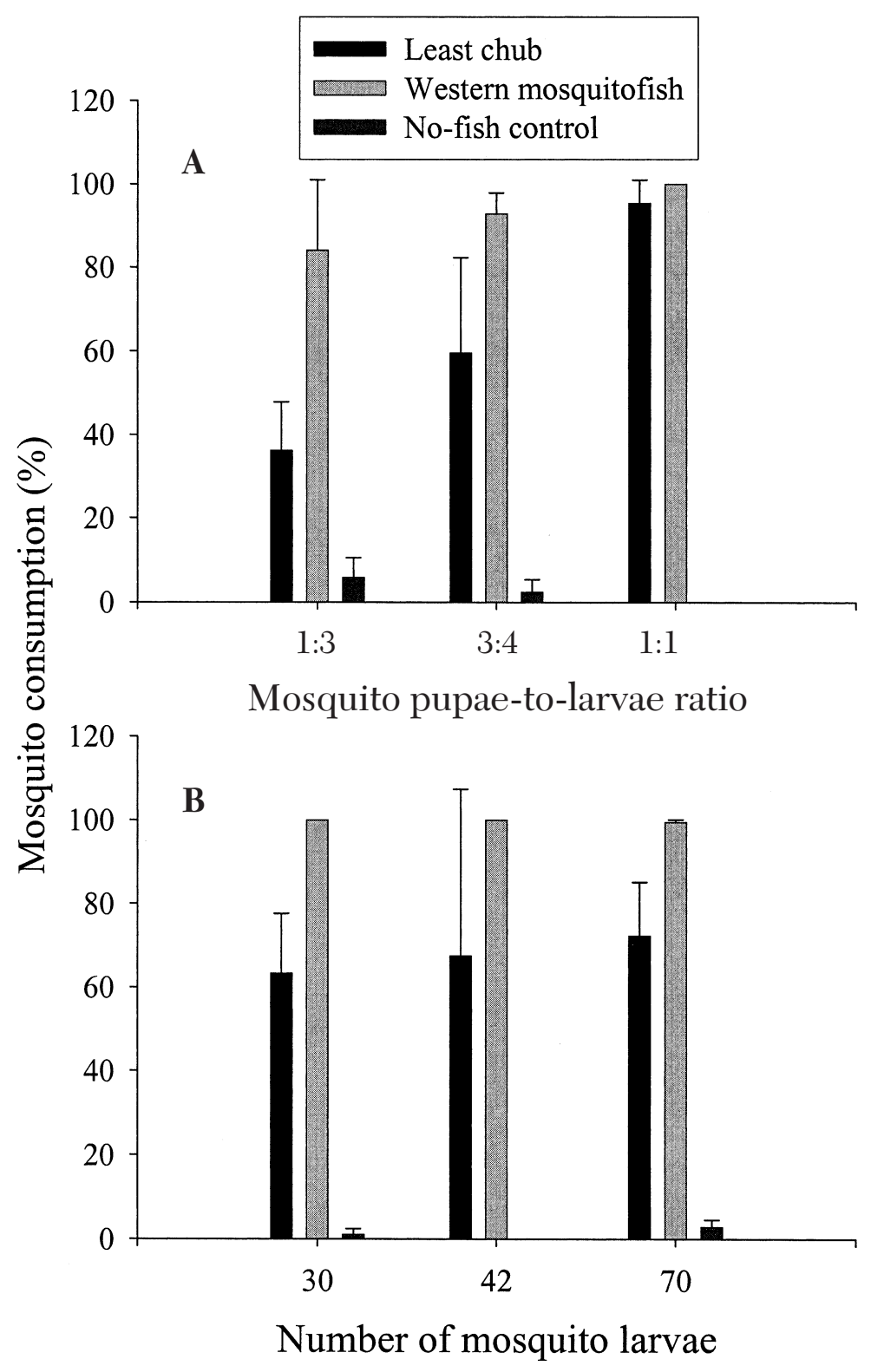

Fig. 1. (A) Mean consumption of mosquito pupae and larvae fed at 3 different ratios to least chub (Iotichthys phlegethontis) and western mosquitofish (Gambusia affinis). Three replicates were conducted for each treatment (least chub, western mosquitofish, and no-fish control) for each ratio. (B) Mean consumption of mosquito larvae fed at 3 different quantities to least chub and western mosquitofish. Three replicates were conducted for each treatment (least chub, western mosquitofish, and no-fish control) for each ratio. Bars represent standard errors $\left(s_{\bar{x}}\right)$.

These findings are supported by field observations indicating that mosquitoes are part of least chub diets (Rees 1945b, Pendleton and Smart 1954, Sigler and Sigler 1996). Both species neutrally selected mosquito larvae in the presence of other prey, indicating that both fish would consume mosquito larvae relative to their abundance. Consumption of mosquitoes, especially the high consumption of pupae and neutral selection for mosquitoes, indicate that least chub potentially could be an indigenous replacement for western mosquitofish. 


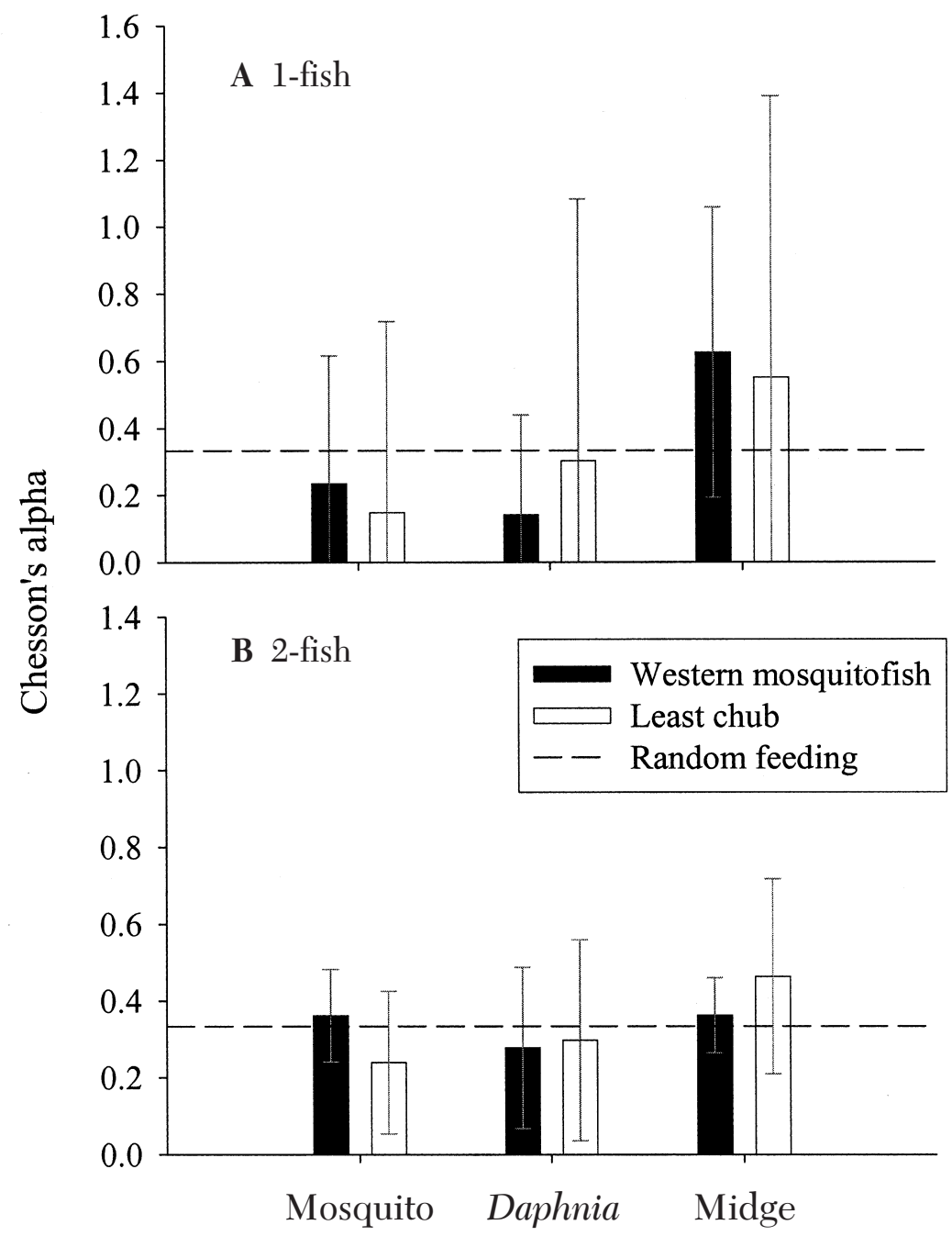

Fig. 2. Mean prey selection by least chub and western mosquitofish for mosquito larvae, Daphnia magna, and midge larvae as determined by Chesson's selectivity coefficient: (A) 1-fish experiments and (B) 2-fish experiments. Bars represent $95 \%$ confidence intervals. Positive selectivity was assumed when the $95 \%$ confidence interval was above the random feeding line (dashed), neutral selectivity when the $95 \%$ confidence interval overlapped the random feeding line, and negative selectivity when the $95 \%$ confidence interval was below the random feeding line.

Western mosquitofish, however, consumed significantly more mosquitoes in every trial, except when pupae were equally abundant as larvae. High consumption rates are not unusual for the western mosquitofish, which have been reported to consume over $80 \%$ of their body weight per day (Shakuntala and Reddy 1977, Chipps and Wahl 2004). The effectiveness of western mosquitofish in mosquito control can be attributed to these high feeding rates. High feeding rates of western mosquitofish also indicate the species' ability to negatively impact native aquatic organisms (Rupp 1996, Chipps and Wahl 2004, Leyse et al. 2004). Mills et al. (2004) demonstrated that western mosquitofish negatively impact least chub through both predation and competition for food and habitat. In their studies, young-of-the-year least chub were readily consumed by western mosquitofish, while those not eaten, including adults, experienced reduced growth as a result of competition with western mosquitofish.

An indigenous substitute for western mosquitofish has been sought for years (Haas and Pal 1984, Rupp 1996), but studies attempting to find a replacement have met with limited 
success. Nelson and Keenan (1992) demonstrated that the plains killifish (Fundulus zebrinus) was able to control mosquitoes at levels comparable to western mosquitofish. However, the western mosquitofish provides better mosquito control than threespine stickleback (Gasterosteus aculeatus; Offill and Walton 1999), desert pupfish (Cyprinodon nevadensis amargosae; Castleberry and Cech 1990), and Sacramento blackfish (Orthodon microlepidotus; Cech and Linden 1987). The western mosquitofish has high reproductive potential and can tolerate a wide range of water quality conditions, allowing it to thrive in habitats where indigenous fishes may not survive (Bay 1972). These same characteristics, however, give western mosquitofish the ability to have catastrophic effects on native fauna where they are introduced (Bay 1972, Schoenherr 1981).

Our study was not completely realistic because mosquito consumption and prey selection experiments were conducted in an unnatural environment. In both experiments, prey did not have refugia and were vulnerable to predation by fish. In natural settings mosquito larvae use vegetation to avoid predation. Least chub may prove to be equally or more effective at capturing mosquito larvae when vegetation is present, as is the case for other species of fish (Nelson and Keenan 1992, Homski et al. 1994). Kramer et al. (1987) demonstrated that the inland silverside (Medinia beryllina) and the western mosquitofish were equally ineffective as a mosquito control agent due to the presence of vegetation and alternative prey. Similar results might be expected if the efficacy of least chub and western mosquitofish for mosquito control was compared using vegetation in laboratory experiments or by conducting experiments in a field setting.

Our study demonstrated that the least chub, while not as efficient as the western mosquitofish at consuming mosquito larvae, could potentially be used in mosquito control because it will consume immature mosquitoes even in the presence of other prey. Further studies should compare the efficacy of least chub and western mosquitofish for mosquito control in field settings. If least chub prove as effective in mosquito control as western mosquitofish in field settings, managers would prefer indigenous least chub to western mosquitofish for conservation reasons. Least chub are not only native to Utah, but can ably survive drought conditions and harsh winters. Western mosquitofish are poorly adapted for such conditions (Rees 1934, Nelson and Keenan 1992). Scientists should continue to investigate indigenous fish as substitutes for the western mosquitofish in mosquito control so that negative effects of western mosquitofish on native fauna can be minimized.

\section{ACKNOWLEDGMENTS}

Funding was provided by the Utah Division of Wildlife Resources and the Utah Reclamation Mitigation and Conservation Commission. We thank the Davis County Mosquito Abatement District for providing western mosquitofish for our experiments. We thank Mellisa Harvey for assistance in data collection.

\section{Literature Cited}

Bay, E.C. 1972. Mosquitofish: a controversial friend to mosquito control. Pest Control 40(12):32-33.

BENCE, J.R. 1988. Indirect effects and biological control of mosquitoes by mosquitofish. Journal of Applied Ecology 25:505-521.

Castleberry, D.T., and J.J. Cech, JR. 1990. Mosquito control in wastewater: a controlled and quantitative comparison of pupfish (Cyprinodon nevadensis amargosae), mosquitofish (Gambusia affinis), and guppies (Poecilia reticulata) in sago pondweed marshes. Journal of the American Mosquito Control Association 6:223-228.

Cech, J.J., JR., And A.L. Linden. 1987. Comparative larvivorous performances of mosquitofish (Gambusia affinis) and juvenile Sacramento blackfish (Orthodon mirolepidotus) in experimental paddies. Journal of the American Mosquito Control Association 3:35-41.

[CDC] Centers for Disease Control. 2003. Epidemic/ epizootic West Nile virus in the United States: guidelines for surveillance, prevention, and control. Centers for Disease Control, National Center for Infectious Diseases, Fort Collins, CO. Accessed October 2005. Available from: www.cdc.gov/ncidod/dvbid/westnile/ resources/wnvguidelines2003.pdf

Chesson, J. 1983. The estimation and analysis of preferences and its relationship to foraging models. Ecology 70:1227-1235.

Chipps, S.R., And D.H. WahL. 2004. Development and evaluation of a western mosquitofish bioenergetics model. Transactions of the American Fisheries Society 133:1150-1162.

GoodselL, J.A., AND L.B. KaTs. 1999. Effect of introduced mosquitofish on Pacific treefrogs and the role of alternative prey. Conservation Biology 13:921-924.

HaAs, R., AND R. PAL. 1984. Mosquito larvivorous fishes. Bulletin of the Entomological Society of America 30:17-25.

Homski, D., M. Goren, and A. Gasith. 1994. Comparative evaluation of the larvivorous fish Gambusia affinis and Aphanius dispar as mosquito control agents. Hydrobiologia 284:137-146. 
Kramer, V.L., R. Garcia, and A.E. Colwell. 1987. An evaluation of the mosquitofish (Gambusia affinis) and the inland silverside (Menidia beryllina) as mosquito control agents in California wild rice fields. Journal of the American Mosquito Control Association 3:626-632.

Leyse, K.E., S.P. Lawler, and T. Strange. 2004. Effects of an alien fish, Gambusia affinis, on an endemic California fairy shrimp (Linderiella occidentalis): implications for conservation of diversity in fishless waters. Biological Conservation 118:57-65.

Linden, A.L., AND J.J. CECH. 1990. Prey selection by mosquitofish (Gambusia affinis) in California rice fields: effect of vegetation and prey species. Journal of the American Mosquito Control Association 6:115-120.

LydeARD, C., AND M.C. BELK. 1993. Management of indigenous fish species impacted by introduced mosquitofish: an experimental approach. Southwestern Naturalist 38:370-373.

Mills, M.D., R.B. Rader, AND M.C. BelK. 2004. Complex interactions between native and invasive fish: the simultaneous effects of multiple negative interactions. Oecologia 141:713-721.

Nelson, S.M., AND L.C. KeEnan. 1992. Use of an indigenous fish species (Fundulus zebrinus) in a mosquito abatement program: a field comparison with the mosquitofish (Gambusia affinis). Journal of the American Mosquito Control Association 8:301-304.

Offill, Y.A., AND W.E. WALton. 1999. Comparative efficacy of the threespine stickleback (Gasterosteus aculeatus) and the mosquitofish (Gambusia affinis) for mosquito control. Journal of the American Mosquito Control Association 15:380-390.

Pendelton, R.C., And E.W. Smart. 1954. A study of the food relations of the least chub (Iotichthys phlegethontis Cope), using radioactive phosphorus. Journal of Wildlife Management 18:226-228.
Perkins, M.J., L.D. Lentsch, And J. MizZi. 1998. Conservation agreement and strategy for least chub (Iotichthys phlegethontis). Utah Division of Wildlife Resources, Salt Lake City.

ReEs, D.M. 1934. Notes on mosquito fish in Utah, Gambusia affinis (Baird and Girard). Copeia 1934:157-159.

. 1945a. Supplemental notes on mosquito fish in Utah, Gambusia affinis (Baird and Girard). Copeia 1945:236.

. 1945b. The utilization of fish by a mosquito abatement district: their effectiveness and limitations. Pages 211-216 in Proceedings of the 32nd Annual Meeting of the New Jersey Mosquito Extermination Association.

Rupp, H.R. 1996. Adverse assessments of Gambusia affinis: an alternative view for mosquito control practitioners. Journal of the American Mosquito Control Association 12:155-156.

Schoenherr, A.A. 1981. The role of competition in the replacement of native fishes by introduced species. Pages 173-203 in R.J. Naiman and D.L. Soltz, editors, Fishes in North American deserts. Wiley, New York.

ShakUntala, K., AND S.R. REDdy. 1977. Influence of body weight-age on the food intake, growth, and conversion efficiency of Gambusia affinis. Hydrobiologia 55:65-69.

Sigler, W.F., AND J.W. Sigler. 1987. Fishes of the Great Basin, a natural history. University of Nevada Press, Reno.

. 1996. Fishes of Utah, a natural history. University of Utah Press, Salt Lake City.

SPSS, INC. 1996. SPSS ${ }^{\circledR}$ base 7.0 for Windows ${ }^{\mathrm{TM}}$ user's guide. SPSS, Inc., Chicago, IL.

Received 18 October 2005 Accepted 14 March 2006 